\title{
Detection of Y Chromosomal Material in Patients with a 45,X Karyotype by PCR Method
}

\author{
C. Nur Semerci, ${ }^{1}$ N. Lale Satiroglu-Tufan, ${ }^{1}$ Serap Turan, ${ }^{2}$ \\ Abdullah Bereket, ${ }^{2}$ Beyhan Tuysuz, ${ }^{3}$ Elif Yilmaz, ${ }^{3}$ Hulya Kayserili, ${ }^{4}$ \\ Birsen Karaman, ${ }^{4}$ Serap Semiz, ${ }^{5}$ Fusun Duzcan ${ }^{1}$ and Huseyin Bagci ${ }^{1}$ \\ ${ }^{1}$ Department of Medical Biology, Center for Genetic Diagnosis, School of Medicine, Pamukkale \\ University, Denizli, Turkey \\ ${ }^{2}$ Department of Pediatric Endocrinology, School of Medicine, Marmara University, Istanbul, \\ Turkey \\ ${ }^{3}$ Department of Medical Genetics, Cerrahpasa Faculty of Medicine, Istanbul University, Istanbul, \\ Turkey \\ ${ }^{4}$ Department of Medical Genetics, Istanbul Faculty of Medicine, Istanbul University, Istanbul, \\ Turkey \\ ${ }^{5}$ Division of Pediatric Endocrinology, Department of Pediatrics, School of Medicine, Pamukkale \\ University, Denizli, Turkey
}

Semerci, C.N., Satiroglu-Tufan, N.L., Turan, S., Bereket, A., Tuysuz, B., Yilmaz, E., Kayserili, H., Karaman, B., Semiz, S., Duzcan, F. and Bagci, H. Detection of $Y$ Chromosomal Material in Patients with a 45,X Karyotype by PCR Method. Tohoku J. Exp. Med., 2007, 211 (3), 243-249 — A 45,X karyotype is one of the common chromosomal abnormalities characterized by short stature, lack of development of secondary sexual characteristics, webbed neck and cubitus valgus. This phenotype was described by Turner in 1938 and was called Turner syndrome (TS). About 40-60\% of the patients with TS phenotype have a 45,X karyotype, the rest either have a structurally abnormal X or Y chromosome or mosaicism with a second cell line. Determination of $\mathrm{Y}$ chromosome derivatives in patients with a 45,X karyotype is important for the management of these patients due to increased risk of gonadoblastoma. Low level mosaicisim of Y chromosome may be missed by cytogenetic methods. The aim of our study is to analyze cryptic Y chromosome derivatives using $\mathrm{Y}$ specific sequences in 40 Turkish patients with a pure 45,X karyotype. Fourteen different $Y$ specific sequences along the $Y$ chromosome were selected for the detection of cryptic Y chromosome material by PCR analysis. The present study demonstrated that 2 patients with a 45,X karyotype (5\%) have Y specific sequences except sex releated region $Y(S R Y)$. One of them had displayed enhanced virilisation whereas other showed no virilisation. In conclusion, it has been found by PCR analysis that $5 \%$ of patients with a $45, \mathrm{X}$ karyotype have $\mathrm{Y}$ chromosome sequences in the absence of any marker chromosome by cytogenetic analysis. The data also suggest that the patients with a 45,X karyotype should be analyzed for the presence of $Y$ chromosome derivatives by sensitive methods, such as PCR, in order to calculate the future risk of developing gonadoblastoma. — 45,X karyotype; Y sequences; PCR; gonadoblastoma; virilisation (C) 2007 Tohoku University Medical Press

Received November 27, 2006; revision accepted for publication January 29, 2007.

Correspondence: C. Nur Semerci, M.D., Department of Medical Biology, Center for Genetic Diagnosis, School of Medicine, Pamukkale University, Denizli, Turkey.

e-mail: nsemerci@pamukkale.edu.tr 
A 45, X karyotype is one of the common chromosomal abnormalities that occurs in about $1 / 2,500$ live female birth. The phenotype is characterized by short stature, lack of development of secondary sexual characteristics, webbed neck and cubitus valgus. It was described by Turner in 1938 and called Turner syndrome (TS) (Jones 1997). In addition to these features, renal and cardiac anomalies may also be observed (Hall and Gilchrist 1990).

About $40-60 \%$ of the patients with TS phenotype have a $45, \mathrm{X}$ karyotype, and the rest of them either have a structurally abnormal X or Y chromosome or mosaicism with a second cell line. About $5 \%$ of the TS patients have a marker chromosome derived from Y chromosome. With the help of advanced technology on molecular cytogenetics and molecular genetics, hidden $\mathrm{Y}$ chromosome derivatives can be easily demostrated in patients with a 45,X karyotype (Hall and Gilchrist 1990).

Demonstration of the hidden $\mathrm{Y}$ chromosome material in patients with a $45, \mathrm{X}$ karyotype is extremely important, due to the increased risk of developing gonadoblastoma or dysgerminoma in dysgenetic Y-bearing gonads. Hence, it is recommended that the gonads should be removed before hormone treatment (Gibbons et al. 1999; Gravholt et al. 2000; Mazzanti et al. 2005; Pena-Alonso et al. 2005; Brant et al. 2006).

The aim of this study is to analyze the precence of occult Y chromosome derivatives using PCR methods in Turkish patients who have a pure $45, X$ karyotype by conventional cytogenetic techniques.

\section{Materials ANd Methods}

\section{Patients}

Forty Turkish patients with pure a 45,X karyotype were included in this study from four distinct medical centers in Turkey. The average of the patients' age was 12.7 years old (the youngest being at one year of age and the oldest 25 years of age). The referral data revealed that short stature and unvisible or streak-like gonads on ultrasonography (US) as the most common findings. Additioanlly, eight patients had renal anomalies (one renal agenesis, and seven horseshoe or ectopic kidneys) and nine patients had cardiac anomalies. Only one patient had displayed enhanced virilisation at the time of referral.

This project was approved by the ethics committee of Pamukkale University School of Medicine (27.09.2006-08). Written informed consent was obtained from adults and the parents of children younger than 16 years old.

\section{Cytogenetic analysis}

Chromosome analysis had been performed using peripheral blood lymphocytes from all patients at the original medical centers they were referred to. Metaphase chromosomes had been evaluated by GiemsaTripsin-Giemsa (GTG) banding and at least 30 metaphases were analyzed for each patient. The patients with a pure $45, X$ karyotype were included in the study.

\section{Molecular genetic analysis}

Peripheral blood samples were collected from 40 patients with a 45,X karyotype. Four nulliparous healthy females and four healthy males were included in this study as negative and positive control groups, respectively. DNA was isolated by QIAamp DNA Blood Mini Kit (Qiagen, Hilden, Germany) according to the "blood and body fluid protocol" and also by standard salt precipitation technique using peripheral blood samples. Fourteen different $Y$ chromosome specific sequences located along the $\mathrm{Y}$ chromosome were selected for the detection of cryptic Y chromosome material by PCR analysis (Fig. 1).

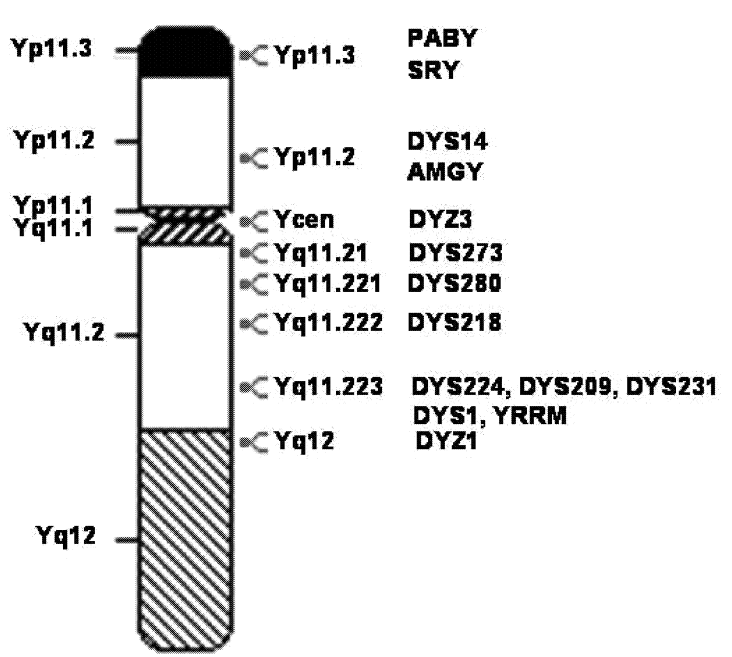

Fig. 1. Ideogram of $Y$ chromosome showing the loci of $\mathrm{Y}$ specific sequences included in this study. 
Designed primer sequences and expected size of the PCR products were summarized in Table 1. PCR reactions were done in a total volume of $50 \mu 1$, including, extracted DNA, 20 pmol of each forward and reverse primers, and $25 \mu 1$ of HotStarTaq Master Mix (containing 2.5 units of HotStarTaq DNA polymerase, 1x PCR buffer with 1.5 $\mathrm{mM} \mathrm{MgCl}$, and $200 \mu \mathrm{M}$ of each dNTP (Qiagen, Hilden, Germany). The thermal cycling was performed as follows: initial activation of HotStarTaq DNA polymerase at $95^{\circ} \mathrm{C}$ for $15 \mathrm{~min}$, followed by 35 cycles of denaturation at $94^{\circ} \mathrm{C}$ for $1 \mathrm{~min}$, annealing at $57^{\circ} \mathrm{C}$ for 1 $\min$ (specific annealing temperature for each primer is summarized in Table 1) and, extension at $72^{\circ} \mathrm{C}$ for $1 \mathrm{~min}$, with final extension at $72^{\circ} \mathrm{C}$ for $10 \mathrm{~min}$. The PCR amplification products were separated by $2 \%$ agarose gel electrophoresis and visualized by exposure to ultraviolet light after ethidium bromide staining.

Peripheral blood samples obtained from four healthy men were used to determine the PCR specificity, sensitivity and optimization as positive controls; whereas peripheral blood samples obtained from four healthy nullipar women served as negative controls. DNA samples from four males, four females and water (no DNA template) were included in each PCR reaction as controls together with the patients' samples. All DNA extractions and PCR reactions were performed by a female technician to avoid the risk of male DNA contamination.

TABLE 1. Primer sequence, product size, annealing temperature and references.

\begin{tabular}{|c|c|c|c|c|}
\hline Primer & Sequence & $\begin{array}{l}\text { Product size } \\
\quad \text { (bp) }\end{array}$ & $\begin{array}{l}\text { Annel. } \\
\text { tem. } .^{\circ} \mathrm{C}\end{array}$ & Reference \\
\hline$P A B Y$ & $\begin{array}{l}\text { 5'-GTACTACCTTTAGAAAACTAGTATTTTCCC-3' } \\
\text { 5'-GAATTCTTAACAGGACCCATTTAGGATTAA-3' }\end{array}$ & 970 & 54 & $\begin{array}{l}\text { Griffiths and Tiwari } \\
\text { (1993) }\end{array}$ \\
\hline$S R Y$ & $\begin{array}{l}\text { 5'-CAGTGTGAAACGGGAGAAAACAGT-3' } \\
\text { 5'-CTTCCGACGAGGTCGATACTTATA-3' }\end{array}$ & 270 & 65 & Nakagome et al. (1991) \\
\hline DYS14 & $\begin{array}{l}\text { 5'-CATCCAGAGCGTCCCTGGCTT-3' } \\
\text { 5'-CCCCACACACATGCACTTACC-3' }\end{array}$ & 198 & 57 & Lo et al. (1990) \\
\hline$A M G Y$ & $\begin{array}{l}\text { 5'-CTGATGGTTGGCCTCAAGCCTGTG-3' } \\
\text { 5'-CCTTGCTCATATTATACTTGACAAAGC-3' }\end{array}$ & 355 & 60 & Nakohori et al. (1991) \\
\hline$D Y Z 3$ & $\begin{array}{l}\text { 5'-ATGATAGAAACGGAAATATG-3' } \\
\text { 5'-AGTAGAATGCAAAGGGCTCC-3' }\end{array}$ & 120 & 57 & $\begin{array}{l}\text { Griffiths and Tiwari } \\
\text { (1993) }\end{array}$ \\
\hline DYS273 & $\begin{array}{l}\text { 5'-AGAAGGGTCTGAAAGCAGGT-3' } \\
\text { 5'-GCCTACTACCTGGAGGCTTC-3' }\end{array}$ & 326 & 59 & Vollrath et al. (1992) \\
\hline DYS280 & $\begin{array}{l}\text { 5'-TCCTACAGATGTCCAAAGTGC-3' } \\
\text { 5'-GATGAGTGACCCCAGAATTG-3 }\end{array}$ & 303 & 60 & Vollrath et al. (1992) \\
\hline DYS218 & $\begin{array}{l}\text { 5'- GGCTCACAAACGAAAAGAAA-3' } \\
\text { 5'- CTGCAGGCAGTAATAAGGGA-3' }\end{array}$ & 274 & 56 & Vollrath et al. (1992) \\
\hline DYS224 & $\begin{array}{l}\text { 5'-GTCTGCCTCACCATAAAACG-3' } \\
\text { 5'- ACCACTGCCAAAACTTTCAA-3' }\end{array}$ & 301 & 56 & Vollrath et al. (1992) \\
\hline DYS209 & $\begin{array}{l}\text { 5'- GTTGGTTCCATGCTCCATAC-3' } \\
\text { 5'- CAGGGAGAGAGCCTTTTACC-3' }\end{array}$ & 261 & 54 & Vollrath et al. (1992) \\
\hline DYS231 & $\begin{array}{l}\text { 5'-GCAGGATGAGAAGCAGGTAG-3' } \\
\text { 5'-CCGTGTGCTGGAGACTAATC-3' }\end{array}$ & 311 & 59 & Vollrath et al. (1992) \\
\hline DYS1 & $\begin{array}{l}\text { 5'-TGTCACACTGCCCTAATCCT-3' } \\
\text { 5'-TGGTCATGACAAAAGACGAA-3' }^{\prime}\end{array}$ & 132 & 60 & Vollrath et al. (1992) \\
\hline YRRM & $\begin{array}{l}\text { 5'-CTCGGATGTCTTATGGTGGAA-3' } \\
\text { 5'-GCATCAACAAGTATGAAATTACT-3' }\end{array}$ & 473 & 60 & Patsalis et al. (1997) \\
\hline$D Y Z 1$ & $\begin{array}{l}\text { 5'-TCCACTTTATTCCAGGCCTGTCC-3' } \\
\text { 5'-TTGAATGGAATGGGAACGAATGG-3' }\end{array}$ & 149 & 62 & Uehara et al. (1999) \\
\hline
\end{tabular}




\section{Results}

$\mathrm{Y}$ chromosome specific sequences $(P A B Y$, SRY, DYS14, AMGY, DYZ3, DYS273, DYS280, DYS218, DYS224, DYS209, DYS231, DYS1, YRRM, DYZ1) used in this study except sex releated region $Y(S R Y)$ were detected in two of the patients (patient \#35 and \#38). SRY (270bp) and glyceraldehyde-3-phosphate dehydrogenase $(G A P D H)(97 \mathrm{bp})$ were co-amplified in a multiplex PCR setting using DNA from these two patients, control male and female, and water without DNA to confirm absence of $S R Y$. Both of the DNA samples from patients were found negative for $S R Y$ (Fig. 2).

Patient \#35 was 13 years old and had short stature, high arched palate, prominent ears, and low set hairline. The patient had no signs of virilisation with completely normal female external genitalia. Abdominal and pelvic US showed unilateral absence of gonad and normal sized uterus after sex steroid replacement and, unilateral renal agenesis. PCR analysis detected the presence of $\mathrm{Y}$ specific sequences included in this study, except $S R Y$ in this patient (Fig. 2). The family was counselled about the health issues associated with the presence of $\mathrm{Y}$ chromosome sequences. The patient was scheduled for gonadal close follow-up and cytogenetic analysis from skin fibroblasts was planned.

Patient \#38 was 4 years old and had ambiguous genitale. Assigned gender was male by the family. On physical examination the patient had short stature, mild micrognathia, prominent and posteriorly rotated ears, high arched palate, and short 4th metacarpal bones. Genital examination revealed penoscrotal hypospadias, small fallus ( 2 $\mathrm{cm}$ in length), severe chordee, bifid scrotum and palpable right testis. Left testis was not palpable. Abdominal ultrasonography and echocardiography were in normal limits. Pelvic US examination demonstrated vagina with no uterus in the pelvis. Scrotal US examination illustrated normal right testis in the scrotum, left testis could not be revealed by inguinal/pelvic US. PCR analysis detected the presence of $\mathrm{Y}$ chromosome specific sequences included in this study except $S R Y$ in this patient (Fig. 2). Additional cytogenetic analysis was performed in blood lymphocytes and skin fibroblasts, but showed no marker chromosome. Pathological examination of both gonads showed the testicular tissue with immature seminiferous tubules. PCR analysis of immature testis tissue DNA sample with DYS14 (testis specific protein $Y[T S P Y]$ ) primers was also found to be positive. The undescended testis was found and removed by laporatomy and the descended testis was scheduled for close follow-up due to the high risk of gonadoblastoma development.

\section{Discussion}

The present study demonstrated that two out of 40 patients (5\%) with a 45,X karyotype have $\mathrm{Y}$ specific sequences detected by PCR analysis. Presence of $\mathrm{Y}$ chromosome derivatives has been suggested as $5 \%$ by conventional cytogenetic methods and $9.2 \%-12 \%$ by flourescence in situ hybridization (FISH) due to the low level of

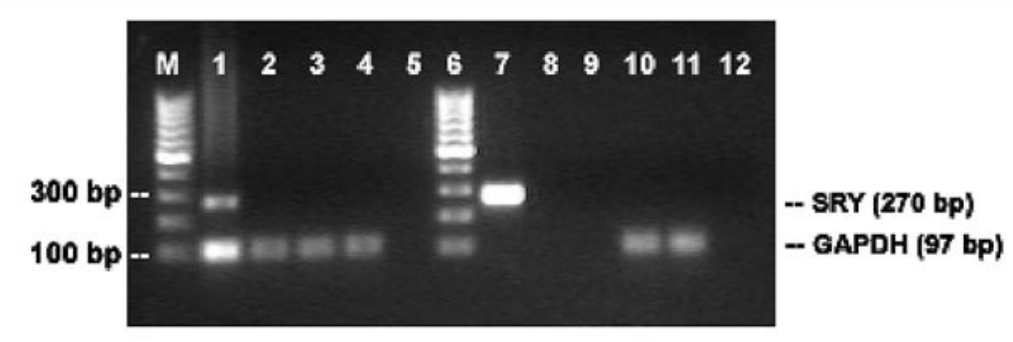

Fig. 2. Multiplex PCR detection of $S R Y$ and $G A P D H$. M, a molecular weight marker; 1, multiplex male control; 2, multiplex patient $35 ; 3$, multiplex patient 38; 4, multiplex female control; 5, multiplex su; 6, marker; 7, SRY male control; 8, SRY female control; 9, SRY water; 10, GAPDH male control; $11, G A P D H$ female control; $12, G A P D H$ water. 
mosaisizm in TS (Gravholt et al. 2000; Quilter et al. 2002). However, the frequency of $Y$ sequences in patients with TS varies from $0 \%$ to $61 \%$ depending on the molecular methods used and the patient population studied. This variability may be caused by the number of the patients with mosaic marker chromosome, selection of the $Y$ chromosome specific primers, different tissues tested and molecular methodology used by different study groups (Kokova et al. 1993; Binder et al. 1995; Coto et al. 1995; Larsen et al. 1995; Patsalis et al. 1997; Osipova et al. 1998; Lopez et al. 1998; Quilter et al. 1998; Mendes et al. 1999; Fernandez-Garcia et al. 2000; Gravholt et al. 2000; Nishi et al. 2002; Alvarez-Nava et al. 2003). Therefore, it is difficult to compare our results with previously reported results.

Our Y chromosome specific primer set was almost similar to the primer set used in the study of Nishi et al. (2002). They demonstrated Y specific sequences in four patients in a study group of 122 patients revealing $3.3 \%$ detection rate. However, all of these patients, who had been positive for Y sequences by PCR, also had mosaic marker chromosome by cytogenetic analysis. The authors could not find any $\mathrm{Y}$ sequence in 66 patients with a $45, \mathrm{X}$ karyotype by PCR. Furthermore, when they performed nested PCR for only $S R Y$ and TSPY sequences, the positivity was found in $14 \%$ of woman controls and $25 \%$ of the patients. In the view of their findings, they concluded that nested PCR could have overestimated the results.

Binder et al. (1995), Coto et al. (1995), Larsen et al. (1995), Fernandez et al. (1996) and Lopez et al. (1998) used similar Y specific sequences and found that the ratio of $\mathrm{Y}$ sequences in patients with a $45, \mathrm{X}$ karyotype were $3.3 \%$, $26.6 \%, 9.1 \%, 11.1 \%, 12 \%$, respectively. Quilter et al. (1998) reported $4 \%(2 / 50)$ in patient have a 45, X karyotype with eight primer set along $\mathrm{Y}$ chromosome. They found low level Y mosaicism in patients with positivity in PCR reactions after additional cytogenetic analysis of 100 metaphases. We also performed additional cytogenetic analysis of 100 metaphases in blood lymphocytes and 70 in metaphases skin fibroblasts in patient
\#38 but could not find any marker chromosome. Bartman et al. (2004) performed molecular genetic studies with three Y-chromosome specific sequences (TSPY, deleted in azoospermia [DAZ], $S R Y$ ) in three different tissue samples (blood, buccal cell, urine) of 30 patients with a $45, X$ karyotype by nested PCR. They found that Y-chromosome specific sequences were positive in $3.4 \%$ in blood, $3.4 \%$ in buccal cell samples and $19.2 \%$ in urine samples. So they suggested that urine samples are more informative due to their embryological origin. Y-chromosome specific sequence positivity results obtained from blood and buccal samples in Bartman's study (2004) are in correlation with our results.

It was surprising that despite having similar Y-chromosome sequences, the degree of virilisation was variable in our two patients, one having severe signs of virilisation and the other showing no signs of virilisation. Several molecular mechanisms and genes identified playing important roles in sex determination and differentiation are described in the literature. Qin and Bishop (2005) demonstrated that $S R Y$ related HMG Box Gene 9 (Sox9) is sufficient for functional testis development producing fertile male mice in the absence of SRY. Testicular tissue was detected in the absence of SRY in our second case. Other genes which are involved in sex determination and differentiation will be tested as planned.

It is well known since 1970 that the presence of Y material in patients with dysgenetic gonads increases the risk of gonadal tumor development such as gonadoblastoma and disgerminoma (Scully 1970; Verp and Simpson 1987). Hsu (1994) suggest that development of gonadoblastoma risk in patients with $\mathrm{Y}$ chromosome mosaicism is lowest in phenotypic males, intermediate $(0.5 \%)$ in patients with ambiguous external genitalia (as in our patient \#38) and the highest (22\%) in phenotypic females (as in our patient \#35). Gonadoblastoma is a mixed germ cell-sex cordstromal tumor developing in dysgenetic gonads. Hormone treatment in patients with a 45,X karyotype also increases the risk for gonadal tumor development (Page 1987) Hence, detection of cryptic Y chromosome derivatives is so important 
for the management and close follow-up of these patients, that should be emphasized by appropriate genetic counselling.

Our patient \#35 with the presence of $Y$ sequences also had unilateral renal agenesis. Coto et al. (1995) suggested that renal anomalies may be associated with the presence of Y-chromosome sequences. Bilge et al. (2000) has reported the frequency of renal anomalies in patients with a pure $45, \mathrm{X}$ karyotype as $51.1 \%$. In our series of 40 patients eight patients had renal anomalies, and the frequency rate being $20 \%$. The seven renal anomalies other than renal agenesis were horseshoe or ectopic kidneys and the frequency of detection being $17.5 \%$. This rate has been reported as $17.7 \%$ in the study of Bilge et al. (2000).

In conclusion, we found that $5 \%$ of patients with a 45, X karyotype have $\mathrm{Y}$ chromosome sequences by PCR analysis even in the absence of any marker chromosomes. Our data also supports that the patients with a $45, \mathrm{X}$ karyotype should be analyzed for the presence of $\mathrm{Y}$ chromosome derivatives by sensitive molecular methods to predict the future risk of gonadoblastoma development.

\section{Acknowledgments}

Authors thank Prof. Dr. Seher Basaran, Department of Medical Genetics, Istanbul Medical Faculty, Istanbul University, Istanbul, Turkey, for her contribution to the patient group. This project is supported by Pamukkale University Scientific Research Grants Fund.

\section{References}

Alvarez-Nava, F., Soto, M., Sanchez, M.A., Fernandez, E. \& Lanes, R. (2003) Molecular analysis in Turner syndrome. J. Pediatr., 142, 336-340.

Bartmann, A.K., Ramos, E.S., Caetano, L.C., Rios, A.F.L. \& Vila, R.A. (2004) TSPY detection in blood, Buccal, and Urine cells of patients with 45,X karyotype. Am. J. Med. Genet., 130A, 320-321.

Bilge, I., Kayserili, H., Emre, S., Nayir, A., Sirin, A., Tukel, T., Bas, F., Kilic, G., Basaran, S., Gunoz, H. \& Apak, M. (2000) frequency of renal malformations in Turner syndrome: analysis of 82 Turkish children. Pediatr. Nephrol., 14, 1111-1114.

Binder, G., Koch, A., Wajs, E. \& Ranke, M.N. (1995) Nested polymerase chain reaction study of 53 cases with Turner's syndrome: Is cytogenetically undetected Y mosaicism common? J. Clin. Endocrinol. Metab., 80, 3532-3536.
Brant, W.O., Rajimwale, A., Lovell, M.A., Travers, S.H., Furness, P.D., Sorensen, M., Oottamasathien, S. \& Kolye, M.A. (2006) Gonadoblastoma and Turner syndrome. $J$. Urol., 175, 1858-1860.

Coto, E., Toral, J.F., Menendez, M.J., Hernando, I., Plasencia, A., Benavides, A. \& Lopez-Larrea, C. (1995) PCR-based study of the presence of $\mathrm{Y}$ chromosome sequences in patients with Ullrich-Turner syndrome. Am. J. Med. Genet., 57, 393-396.

Fernandez-Garcia, R., Garcia-Doval, S., Costoya, S. \& Pasaro, E. (2000) Analysis of sex chromosome aneuploidy in 41 patients with Turner syndrome: A study of 'hidden' mosaicism. Clin. Genet., 58, 201-208.

Gibbons, B., Tan, S.Y., Yu, C.C.-W., Cheah, E. \& Tan, H.L. (1999) Risk of gonadoblastoma in female patients with Y chromosome abnormalities and dysgenetic gonads. $J$. Paediatr. Child Health, 35, 210-213.

Gravholt, C.H., Fedder, J., Naeraa, R.V. \& Müler, J. (2000) Occurrence of gonadoblastoma in females with Turner syndrome and Y chromosome material: A population study. J. Clin. Endocrinol. Metab., 85, 3199-3202.

Griffits, R. \& Tiwari, B. (1993) Primers for the differantial amplification of the sex-determining region $\mathrm{Y}$ gene in a range of mammal species. Mol. Ecol., 2, 405-406

Hall, J. \& Gilchrist D. (1990) Turner syndrome and its variants. Pediatr. Clin. North Am., 37, 1421-1440.

Hsu, L.Y. (1994) Phenotype/karyotype correlations of Y chromosome aneuploidy with emphasis on structural aberrations in postnatally diagnosed cases. Am. J. Med. Genet., 53, 108-40.

Jones, K.L. (1997) Smith's Recognizable Patterns Of Human Malformation. 5th ed. W.B. Saunders Company, Philadelphia, pp. 81-87.

Kokova, M., Siegel, S.F., Wenger, S.L., Lee, P.A. \& Trucco, M. (1993) Detection of Y chromosome sequences in Turner's syndrome by Southern blot analysis of amplified DNA. Lancet, 342, 140-143.

Larsen, T., Gravholt, C.H., Tillebeck, A., Larsen, H., Jensen, M.B., Nielsen, J. \& Friedrich, U. (1995) Parental origin of the $\mathrm{X}$ chromosome, $\mathrm{X}$ chromosome mosaicism and screening for 'hidden' $\mathrm{Y}$ chromosome in 45,X Turner syndrome ascertained cytogenetically. Clin. Genet., 48, 6-11.

Lopez, M., Canto, P., Aguinaga, M., Torres, L., Cervantes, A., Alfaro, G., Mendez, J. \& Kofman-Alfaro, S. (1998) Frequency of $\mathrm{Y}$ chromosomal material in Mexican patients with Ullrich-Turner syndrome. Am. J. Med. Genet., 76, 120-124.

Mazzanti, L., Cicognani, A., Baldazzi, L., Bergamaschi, R., Scarano, E., Strocchi, S., Nicoletti, A., Mencarelli, F., Pittalis, M., Forabbosco, A. \& Cacciari, E. (2005) Gonadoblastoma in Turner Syndrome and Y-chromosome-derived material. Am. J. Med. Genet., 135A, 150-154.

Mendes, J.R.T., Strufaldi, M.W.L., Decelo, R., Moises, R.M.M.S., Vieira, J.G., Kasamatsu, T.S., Galera, M.F., Andrade J.A.D. \& Verreschi, I.T.N. (1999) Y-chromosome identification by PCR and gonadal hystopathology in Turner's syndrome without overt Y-mosaicism. Clin. Endocrinol., 50, 19-26.

Nakagome, Y., Seki, S., Fukutani, K., Nagafuchi, S., Nakahori, Y. \& Tamura, T. (1991) PCR detection of distal Yp sequences in an XX true hermaphrodite. Am. J. Med. Genet., 41, 112-114.

Nakohori, Y., Hamano, Y., Iwaya, M. \& Nakagome, Y. (1991) Sex identification by polymerase chain reaction using X-Y 
homologous primer. Am. J. Med. Genet., 39, 472-473.

Nishi, M.Y., Domenice, S., Medeiros, M.A., Mendonca, B.B. \& Billerbeck, A.E.C. (2002) Detection of Y-specific sequences in 122 patients with Turner syndrome: Nested PCR is not a reliable method. Am. J. Med. Genet., 107, 299-305.

Osipova, G.R., Karmanov, M.E., Kozlova, S.I. \& Evgrafov, O.V. (1998) PCR detection of Y-specific sequences in patients with Ullrich-Turner syndrome: Clinical implications and limitations. Am.J. Med. Genet., 76, 283-287.

Page, D.C. (1987) Hypothesis: A Y -chromosomal gene causes gonadoblastoma in dysgenetic gonads. Development, 101, Suppl., 151-155.

Patsalis, P.C., Hadjimarcou, M.I., Velissariou, V., Kitsiuo-Tzeli, S., Zera, C., Syrrou, M., Lyberatou, E., Tzesou, A., Gala, A. \& Skordis, N. (1997) Supernumerary marker chromosomes (SMCs) in Turner syndrome are mostly derived from the Y chromosome. Clin. Genet., 51, 184-190.

Pena-Alonso, R., Nieto, K., Alvarez, R., Palma, I., Najera, N., Erana, L., Dorantes, L.M., Kofman-Alfora, S. \& Queipo, G. (2005) Distribution of Y-chromosome-bearing cells in gonadoblastoma and dysgenetic testis in $45, \mathrm{X} / 46, \mathrm{XY}$ infants. Modern Pathology, 18, 439-445.

Qin, Y. \& Bishop, C.E. (2005) Sox9 is sufficient for functional testis development producing fertile male mice in the absence of Sry. Hum. Mol. Genet., 14, 1221-1229.
Quilter, C.R., Taylor, K., Conway, G.S., Nathwani, N. \& Delhanty, J.D.A. (1998) Cytogenetic and molecular investigations of $\mathrm{Y}$ chromosome sequences and their role in Turner syndrome. Ann. Hum. Genet., 66, 99-106.

Quilter, C.R., Nathwani, N., Conway, G.S., Stanhope, R., Ralph, D., Bahadur,G., Serhal, P., Taylor, K. \& Delhanty, J.D. (2002) A comparative study between infertile males and patients with Turner syndrome to determine the influence of sex chromosome mosaicism and the breakpoints of structurally abnormal Y chromosomes on phenotypic sex. $J$. Med. Genet., 39, 80.

Scully, R.E. (1970) Gonadoblastoma. A review of 74 cases. Cancer, 25, 1340-1356.

Uehara, S., Funato, T., Yaegashi, N., Suziki, H., Sato, J., Sasaki, T. \& Yajima, A. (1999) SRY mutation and Tumor formation on the gonads of XY pure gonadal dysgenesis patients. Cancer Cell Cytogenet., 113, 78-84.

Verp, M.S. \& Simpson, J.L. (1987) Abnormal sexual differentiation and neoplasia. Cancer Genet. Cytogenet., 25, 191-218.

Vollrath, D., Foote, S., Hilton, A., Brown, L.G., Beer-Romero, P., Bogan, J.S. \& Page, D. (1992) The human Y chromosome: A 43-interval map based on naturally occurring deletions. Science, 258, 52-59. 